\title{
Comparison of open and robotic-assisted prostatectomy: The University of British Columbia experience
}

\author{
Louis-Olivier Gagnon, MD; S. Larry Goldenberg, MD, FRCSC; Kenny Lynch, MD; Antonio Hurtado, MD; \\ Martin E. Gleave, MD, FRCSC
}

The Vancouver Prostate Centre and Department of Urologic Sciences, University of British Columbia, Vancouver, BC

See related article on page 98 .

Cite as: Can Urol Assoc J 2014;8(3-4):92-7. http://dx.doi.org/10.5489/cuaj.1707 Published online April 14, 2014.

\section{Abstract}

Introduction: We assessed outcomes and costs of open prostatectomy (OP) versus robotic-assisted prostatectomy (RAP) at a single tertiary care university hospital.

Methods: We retrospectively analyzed 200 consecutive OP by 1 experienced open surgeon (MG) and 200 consecutive RAP by an experienced open surgeon (SLG), after allowing for a short learning curve of 70 cases.

Results: The 2 groups had similar demographics, including mean age (64.7 vs. 64.2) and mean body mass index (27.2 vs. 27.2). The OP group had a higher proportion of higher risk cancers compared to the RAP group (32.5\% vs. 8.5\%). Mean skin-to-skin operative room time was less for the OP (114.2 vs. 234.1 minutes). Transfusion rates were similar at $1.5 \%$ with OP compared to $3.5 \%$ with RAP. The mean length of stay was 1.78 days for OP compared to 1.76 days for RAP, for the last 100 patients in each group. The OP group had more high-grade disease in the prostatectomy specimen, with Gleason $\geq 8$ in $23.5 \%$ compared to $3.5 \%$ in the RAP group. Positive surgical margin rates were comparable at $31 \%$ for OP and $24.6 \%$ for RAP, and remained similar after stratification for pT2 and pT3 disease. The grade I and II perioperative complication rate (ClavienDindo classification) was lower in the OP group (8.5\% vs. 20\%). Postoperative stress urinary incontinence rates $(4.8 \%$ for OP and $4.6 \%$ for RAP) and biochemical-free status (91.8\% for OP and 96\% for RAP) did not differ at 12 months post-surgery. The additional cost of RAP was calculated as $\$ 5629$ per case. The main limitations of this study are its retrospective nature and lack of validated questionnaires for evaluation of postoperative functional outcomes. Conclusion: While hospital length of stay, transfusion rates, positive surgical margin rates and postoperative urinary incontinence were similar, OP had a shorter operative time and a lower cost compared to the very early experience of RAP. Future parallel prospective analysis will address the impact of the learning curve on these outcomes.

\section{Introduction}

Prostate cancer constitutes a major health problem in Canada and is the most common cancer among Canadian men and the third leading cause of death. ${ }^{1}$ Treatment options include active surveillance, surgery and radiation therapy. ${ }^{2}$ Over the past decades, there has been ongoing evolution and improvements to surgery. While radical open prostatectomy (OP) has been the gold standard treatment for decades, the da Vinci (Intuitive Surgical) radical robotic-assisted prostatectomy (RAP) has challenged the open approach with its 3D high-definition vision and advanced instrumentation. There is ongoing debate as to which approach is preferable and whether there are differences in outcomes between these approaches.

RAP has become the most common surgical approach in the United States. Lowrance and colleagues found that $67 \%$ of radical prostatectomies were done robotically among urologists who underwent board certification or recertification in 2010. ${ }^{3}$ In addition, RAP has become the most common robotically assisted surgical procedure performed in general. ${ }^{4}$ This widespread use of the robot, despites its added costs, has progressed in the absence of data showing superiority or equivalence of RAP over OP. ${ }^{5}$ This is due in part to widespread marketing by institutions and manufacturers of RAP and public perception that new technology is inherently better.

We examine patient outcomes and financial consequences of introducing a da Vinci robotics system into an experienced academic urology centre by comparing consecutive open and robotic prostatectomy cases performed by 2 experienced surgeons.

\section{Methods}

Retrospective analysis was performed on 200 patients operated on by 1 experienced open surgeon (MG) and 200 con- 
secutive patients treated by an experienced open (but not laparoscopically-trained) surgeon early in his robotic experience (SLG). Both surgeons have performed more than 2000 open RPs with over 20 years of experience between them. The RAP surgeon had a short learning curve of 70 RAP cases prior to this study.

The surgical technique for the open surgery follows the same principles as the anatomic radical retropubic prostatectomy described by Walsh and colleagues. ${ }^{6}$ However, to improve outcomes, we modified the perioperative management of patients undergoing $\mathrm{OP}$, including using a shorter incision (upper limit four finger-breadth below the umbilicus), avoiding a surgical drain if the anastomosis was watertight, using an incisional injection of local anesthesia, using an analgesia with ketorolac infusion, and encouraging hospital discharge on postoperative day 1 . The surgical technique for the robotic-assisted surgery follows the same principles as the standardized technique, the "Vattikuti Institute Prostatectomy," as described by Menon and colleagues. ${ }^{7}$

Data were collected prospectively through the patient database at the Vancouver Prostate Centre. Captured data included demographics, baseline tumour characteristics, perioperative complications, hospital length of stay, surgical margin status, postoperative stress urinary incontin- ence (defined as patient-reported use of more than 1 pad per day) and erectile dysfunction (defined as insufficient for sexual intercourse).

Differences between groups were assessed with the Student t-test for continuous variables and with the Fisher exact test for categorical variables. A $p$ value $\leq 0.05$ was considered statistically significant. Software used for statistical analysis was GraphPad QuickCalcs (GraphPad Software, Inc., La Jolla, CA).

\section{Results}

The 2 groups shared similar demographics, including mean age (64.7 vs. 64.2$)$, mean body mass index (27.2 vs. 27.2), and rate of prior abdominal surgery ( $31 \%$ vs. $27 \%$ ) (Table 1). Compared to the RAP group, the OP group had higher baseline mean prostate-specific antigen (PSA) levels (11.2 vs. 6.6, $p<0.0001$ ), a higher proportion of Gleason score $\geq 8(30 \%$ vs. $7 \%, p=0.0027)$, and a higher proportion of high-intermediate $(22 \%$ vs. $10.5 \%, p=0.0027)$ and high-risk $(32.5 \%$ vs. $8.5 \%, p<0.0001)$ cancers.

Operative room time was less for the open cases, with mean skin-to-skin time of 114.2 versus 234.1 minutes (Table 2). Pelvic lymph node dissection was performed less often

\begin{tabular}{|c|c|c|c|}
\hline & Open $(n=200)$ & Robotic (n=200) & $p$ value \\
\hline Age, mean (SD) & $64.65(7.204) n=200$ & $64.22(7.065) n=200$ & 0.5471 \\
\hline BMI, mean (SD) & $27.23(4.315) \mathrm{n}=195$ & $27.16(3.271) n=199$ & 0.8559 \\
\hline Prior abdominal surgery, no. (\%) & $62(31 \%)$ & $54(27 \%)$ & 0.4406 \\
\hline $\begin{array}{l}\text { Preop urinary symptoms, mean }(\$ \\
\text { - IPSS score } \\
\text { - Bother score }\end{array}$ & $\begin{array}{l}9.41(7.651) \mathrm{n}=172 \\
1.70(1.612) \mathrm{n}=172\end{array}$ & $\begin{array}{l}8.39(7.100) n=194 \\
1.77(1.491) n=194\end{array}$ & $\begin{array}{l}0.1868 \\
0.6664\end{array}$ \\
\hline $\begin{array}{l}\text { Baseline erectile function } \\
\text { - SHIM score, mean (SD) }\end{array}$ & $17.02(8.013) \mathrm{n}=157$ & $17.93(7.841) \mathrm{n}=177$ & 0.2955 \\
\hline $\begin{array}{l}\text { AJCC clinical stage, no. (\%) } \\
- \text { T1c or less } \\
\text { - T2 } \\
\text { - T3 or more }\end{array}$ & $\begin{array}{c}78(39 \%) \\
105(52.5 \%) \\
15(7.5 \%) \\
2(1 \%)\end{array}$ & $\begin{array}{c}97(48.5 \%) \\
98(49 \%) \\
5(2.5 \%) \\
0\end{array}$ & $\begin{array}{c}0.0695 \\
0.5485 \\
0.0365^{*} \\
0.4987\end{array}$ \\
\hline $\begin{array}{l}\text { Gleason score on TRUS/BX, no. } \\
\text { - Gleason } 6 \\
\text { - Gleason } 7 \\
\text { - Gleason } 8 \text { or more } \\
\text { - Unknown }\end{array}$ & $\begin{array}{c}49(24.5 \%) \\
91(45.5 \%) \\
60(30 \%) \\
0\end{array}$ & $\begin{array}{c}97(48.5 \%) \\
89(44.5 \%) \\
13(6.5 \%) \\
1(0.5 \%)\end{array}$ & $\begin{array}{c}0.0001^{*} \\
0.9200 \\
0.0001^{*} \\
1.0000\end{array}$ \\
\hline $\begin{array}{l}\text { Prostate cancer risk level } \\
\text { - Low risk } \\
\text { - Low-intermediate risk } \\
\text { - High-intermediate risk } \\
\text { - High risk }\end{array}$ & $\begin{array}{c}42(21 \%) \\
49(24.5 \%) \\
44(22 \%) \\
65(32.5 \%)\end{array}$ & $\begin{array}{c}87(43.5 \%) \\
75(37.5 \%) \\
21(10.5 \%) \\
17(8.5 \%)\end{array}$ & $\begin{array}{l}0.0001^{*} \\
0.0068^{*} \\
0.0027^{*} \\
0.0001^{*}\end{array}$ \\
\hline Prostate size, mean (SD) & $35.22(24.088) n=129$ & $36.93(23.978) n=148$ & 0.5551 \\
\hline $\begin{array}{l}\text { PSA value, mean (SD) } \\
-<10 \\
-10 \text { to } 20 \\
->20\end{array}$ & $\begin{array}{c}11.16(11.884) \mathrm{n}=200 \\
138(69 \%) \\
41(20.5 \%) \\
21(10.5 \%)\end{array}$ & $\begin{array}{c}6.57(4.352) \mathrm{n}=200 \\
177(88.5 \%) \\
19(9.5 \%) \\
4(2 \%)\end{array}$ & $\begin{array}{l}0.0001^{*} \\
0.0001^{*} \\
0.0030^{*} \\
0.0006^{*}\end{array}$ \\
\hline
\end{tabular}


Gagnon et al.

in the more favourable group of RAP patients ( $82.5 \%$ of OP vs. $19.5 \%$ of RAP). While the OP group had a higher mean blood loss of (402.8 vs. $287.5 \mathrm{~mL}$ ), transfusion rates were similar at $1.5 \%(3 / 200)$ in the OP group compared to $3.5 \%$ $(7 / 200)$ in the RAP group. When RAP was introduced, an aggressive care pathway was implemented for all prostatectomies, targeting discharge on day 1 or day 2 . The mean length of stay for OP (1.78 days) decreased to the equivalent of RAP (1.76 days).

Grade I and II perioperative complications (ClavienDindo classification) were lower in the OP group (8.5\% vs. $20 \%, p=0.0071)$. Most of these were related to transient paralytic ileus from the transabdominal approach. In the earliest cases, several men required transfusions and there were several anastomotic leaks. Time to postoperative catheter removal was shorter for the OP compared to RAP groups (Table 2).

Consistent with a higher proportion of high-risk disease at baseline in the OP group, a comparison of prostatectomy pathology revealed higher grade disease in the OP group, with Gleason $\geq 8$ in $23.5 \%$ compared to $3.5 \%$ in the RAP group (Table 3). Despite this difference in case mix, positive surgical margin rates were similar $(p=0.18)$ at $31 \%$ for the OP group overall and $24.6 \%$ for the RAP group. Margin positive rates were also similar after stratification for pT2 (31\% vs. $24.5 \%)$ and pT3 (43.5\% vs. $51.2 \%)$ tumours.

We found similar postoperative outcomes in stress urinary incontinence rates at 12 months for the OP group (4.8\%) and for the RAP group (4.6\%) (Table 4). Erectile dysfunction rates at 12 months were comparable, but showed a trend for better outcomes in the RAP group at $61.5 \%$ versus $72.8 \%$ for the OP group; this is consistent with the lower use of nervesparing approaches associated with higher risk disease. The biochemical-free status at 12 months was similar at $91.8 \%$ and $96 \%$ in the OP and RAP groups, respectively.

The added cost of robotic prostatectomy, calculated as the difference between open and robotic prostatectomy, was calculated as $\$ 5629$ per case. This amount includes the incremental hours of operating room time, additional disposable supplies, depreciation and service contract costs associated with the robot.

\section{Discussion}

Healthcare costs are growing at unsustainable rates, driven in part by the development of innovative technologies that tend to improve medical outcomes and increase cost. Novel technologies that are either superior, or at least non-inferior and less expensive, can be particularly beneficial. Examples of the least cost-effective urological innovations include extracorporeal shock wave lithotripsy, intermittent androgen suppression, and active surveillance in localized prostate cancer. ${ }^{8}$ In health care, these decrementally cost-effective innovations are rare since medicine is a distinctly "price insensitive" market, in part because incentives to control costs for physicians and patients are lacking.

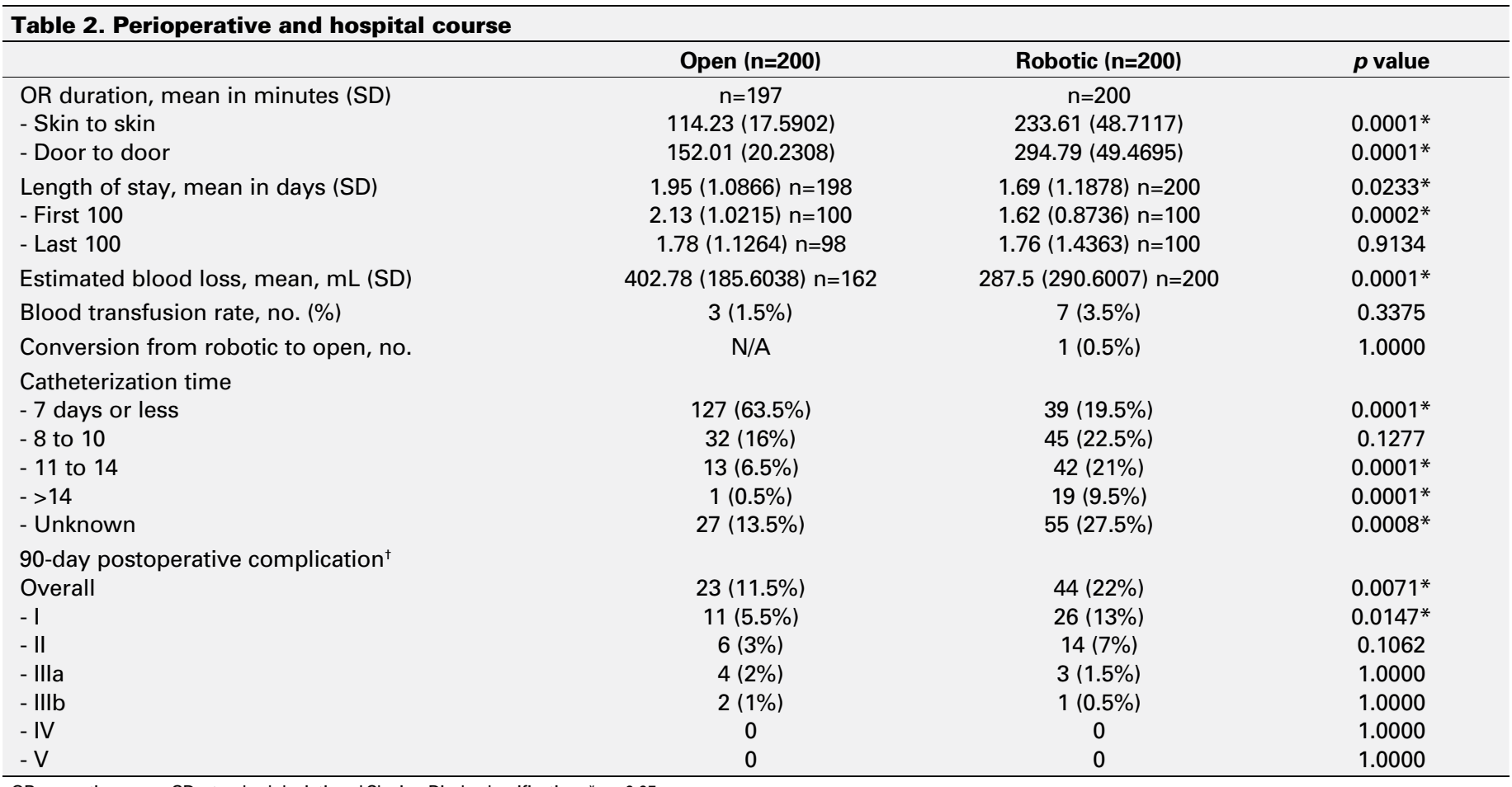

OR: operative room; SD: standard deviation. + Clavien-Dindo classification. ${ }^{*} p<0.05$ 


\begin{tabular}{|c|c|c|c|}
\hline & Open & Robotic & $p$ value \\
\hline $\begin{array}{l}\text { Gleason score } \\
\text { - Gleason } 6 \\
\text { - Gleason } 7 \\
\text { - Gleason } 8 \text { or more } \\
\text { - Tx or Unknown }\end{array}$ & $\begin{array}{c}12(6 \%) \\
125(62.5 \%) \\
47(23.5 \%) \\
16(8 \%)\end{array}$ & $\begin{array}{c}44(22 \%) \\
136(68 \%) \\
7(3.5 \%) \\
13(6.5 \%)\end{array}$ & $\begin{array}{c}0.0001^{*} \\
0.2937 \\
0.0001^{*} \\
0.7004\end{array}$ \\
\hline $\begin{array}{l}\text { Positive margins, no. } \\
\text { (\%) } \\
\text { - Overall } \\
\text { - PT2 } \\
\text { + Gleason } 6 \\
\text { + Gleason } 7 \\
\text { + Gleason } 8 \text { or more } \\
\text { + Unknown } \\
\text { - PT3 or more } \\
\text { + Gleason } 6 \\
\text { + Gleason } 7 \\
\text { + Gleason } 8 \text { or more } \\
\text { + Unknown } \\
\text { - Unknown }\end{array}$ & $\begin{array}{c}62 / 200(31 \%) \\
25 / 115(21.7 \%) \\
3 / 12(25 \%) \\
20 / 82(24.4 \%) \\
1 / 13(7.7 \%) \\
1 / 8(12.5 \%) \\
37 / 85(43.5 \%) \\
0 \\
14 / 43(32.6 \%) \\
18 / 34(52.9 \%) \\
5 / 8(82.5 \%) \\
0\end{array}$ & $\begin{array}{c}49 / 199(24.6 \%) \\
27 / 156(17.3 \%) \\
8 / 42(19 \%) \\
16 / 97(16.5 \%) \\
2 / 6(33.3 \%) \\
1 / 11(9.1 \%) \\
22 / 43(51.2 \%) \\
2 / 2(100 \%) \\
19 / 39(48.7 \%) \\
1 / 1(100 \%) \\
0 / 1(0 \%) \\
1\end{array}$ & $\begin{array}{l}0.1801 \\
0.4354 \\
0.6926 \\
0.1969 \\
0.2219 \\
1.0000 \\
0.4560 \\
1.0000 \\
0.1774 \\
1.0000 \\
0.4444 \\
1.0000\end{array}$ \\
\hline $\begin{array}{l}\text { Extraprostatic } \\
\text { extension, no. (\%) }\end{array}$ & $82 / 200(41 \%)$ & 40/199 (20.1\%) & $0.0001^{*}$ \\
\hline $\begin{array}{l}\text { Seminal vesicle } \\
\text { invasion, no. (\%) }\end{array}$ & $31 / 200(15.5 \%)$ & $13 / 199(6.5 \%)$ & $0.0061^{*}$ \\
\hline $\begin{array}{l}\text { Lymph node status } \\
\text { - Lymph node } \\
\text { dissection, no. (\%) }\end{array}$ & $165 / 200(82.5 \%)$ & $39 / 200$ (19.5\%) & $0.0001 *$ \\
\hline $\begin{array}{l}\text { - No. nodes collected, } \\
\text { mean }\end{array}$ & $5.41(4.694)$ & $3.85(2.242)$ & $0.0448 *$ \\
\hline - Positive, no. (\%) & $18 / 165$ (10.9\%) & $2 / 39(5.1 \%)$ & 0.3774 \\
\hline
\end{tabular}

The value of new technologically driven innovations is often not fully realized until the procedure becomes widely implemented. With healthcare costs growing at unsustainable rates, it is prudent to evaluate new technologies early and compare costs and outcomes to existing standards to ensure that no harm is being done to the patient population. Further economic analyses are highly dependent on the philosophy and healthcare system of the region or country under consideration.

Treating localized prostate cancer using either OP or RAP has been controversial. Unfortunately, a randomized controlled trial is difficult since patients are more inclined to decide for themselves on a particular surgical approach. Indeed, no randomized trial comparing open surgery and robotic-assisted surgery has been done so far. The published literature varies widely; in fact, some reports favour OP and other RAP.

A large population-based study by $\mathrm{Hu}$ and colleagues found that men undergoing minimally-invasive surgery (compared with open retropubic radical prostatectomy) for prostate cancer had a shorter hospital stay and fewer anastomotic strictures, but had more genitourinary complications, including incontinence and erectile dysfunction. ${ }^{9}$ Schroeck and colleagues reported that after an OP, patients were more likely to be satisfied with their treatment, while those who chose a RAP had higher levels of regret. ${ }^{10}$ Kang and colleagues published a review evaluating the quality of evidence comparing OP to RAP; they concluded that the robotic literature is limited to uncontrolled observational studies, many of which are methodologically poor. ${ }^{11}$

Coelho and colleagues published a review of 58 studies showing similar overall complication rates with decreased operative blood loss and risk of transfusion with RAP. ${ }^{12}$ The rate of positive surgical margins, incontinence and erectile dysfunction was also lower with RAP. Interestingly, the authors reported a $93.5 \%$ potency rate at 12 months following bilateral nerve-sparing RAP versus $60.6 \%$ for OP. A study from the Nationwide Inpatient Sample reported a lower transfusion rate, hospital stay as well as perioperative and postoperative complication rates with RAP. ${ }^{13}$ A metaanalysis by Tewari and colleagues is the largest compilation of prostatectomy patients so far. ${ }^{14}$ This report concluded that RAP is at least equivalent to $\mathrm{OP}$ in terms of margin rates and is associated with decreased perioperative and postoperative complications.

The guidelines from the National Comprehensive Cancer Network state that "In experienced hands, the results of laparoscopic and robotic-assisted approaches appear comparable to open surgical approaches. ${ }^{\prime 15}$ The guidelines from the European Association of Urology state that "Systematic reviews of literature have concluded that laparoscopic and robotic-assisted surgery are followed by significantly lower blood loss and transfusion rate, but the available date are insufficient or of insufficient quality to prove the superiority

Table 4. Postoperative outcomes

\begin{tabular}{|c|c|c|c|}
\hline & Open & Robotic & $\begin{array}{c}p \\
\text { value }\end{array}$ \\
\hline \multicolumn{4}{|l|}{$\begin{array}{l}\text { Incontinence (>1 pad } \\
\text { per day) }\end{array}$} \\
\hline - At 6 months & $18 / 160(11.3 \%)$ & $24 / 169(14.2 \%)$ & 0.5091 \\
\hline - At 12 months & $7 / 145(4.8 \%)$ & $7 / 152$ (4.6\%) & 1.0000 \\
\hline \multicolumn{4}{|l|}{ Erectile dysfunction } \\
\hline - At 6 months, overall & 106/127 (83.5\%) & $121 / 159(76.1 \%)$ & 0.1426 \\
\hline $\begin{array}{l}\text { + Bllateral nerve- } \\
\text { sparing }\end{array}$ & $55 / 72(76.4 \%)$ & 75/106 (70.8\%) & 0.4919 \\
\hline $\begin{array}{l}\text { + Unilateral nerve- } \\
\text { sparing }\end{array}$ & $20 / 23(87 \%)$ & $29 / 36(80.6 \%)$ & 0.7255 \\
\hline + No nerve-sparing & $31 / 32(96.9 \%)$ & $17 / 17(100 \%)$ & 1.0000 \\
\hline $\begin{array}{l}\text { - At } 12 \text { months, overall } \\
+ \text { Bilateral nerve- }\end{array}$ & $91 / 125$ (72.8\%) & $83 / 135$ (61.5\%) & 0.0647 \\
\hline sparing & $46 / 67(68.7 \%)$ & $50 / 95(52.6 \%)$ & 0.0515 \\
\hline $\begin{array}{l}\text { + Unilateral nerve- } \\
\text { sparing }\end{array}$ & $15 / 20(75 \%)$ & $20 / 27(74.1 \%)$ & 1.0000 \\
\hline + No nerve-sparing & $30 / 38(78.9 \%)$ & $13 / 13(100 \%)$ & 0.0958 \\
\hline \multicolumn{4}{|l|}{ Biochemical-free } \\
\hline status & $170 / 178(95.5 \%)$ & $172 / 174(98.9 \%)$ & 0.1046 \\
\hline $\begin{array}{l}-<0.2 \text { at } 6 \text { months } \\
-<0.2 \text { at } 12 \text { months }\end{array}$ & $156 / 170(91.8 \%)$ & $168 / 175(96 \%)$ & 0.1175 \\
\hline
\end{tabular}


of any surgical approach in terms of functional and oncologic outcomes."16 The data from our study clearly support these conclusions. The introduction of robotics into a tertiary centre of excellence in prostate care did not result in a negative impact on patients, but at the same time has not replaced the open prostatectomy as the gold standard. Both procedures, as performed by "best of class" highly experienced operators have similar outcomes. Outcomes may continue to evolve with increased experience. However, in the absence of a randomized controlled trial, we must continue to prospectively monitor all patients to determine whether, in the Canadian healthcare system, the "end (dollar cost and operative room time) will ever justify the means."

In Canada, operating time and resource are precious and limited commodities. In this review, the significantly shorter operating room times associated with OP translated into 3 OP compared to 2 RAP cases being done in an 8.5-hour day. Also, the incremental cost of $\$ 5629$ doubles the total cost of OP. Whether this additional cost associated with RAP is justified remains controversial, and can only be justified by quantifiable improvements in outcome or reduced costs by decreasing hospital stay. The actual cost of RAP is very variable in the literature and the true value may be more obvious when postoperative recovery time is factored in. ${ }^{17}$ In this study, while average blood loss was $115 \mathrm{cc}$ higher with OP, transfusion rates were similar. Low-grade perioperative complications, including paralytic ileus and urinary leak, were higher with RAP and likely associated with the intraperitoneal nature of the approach and the early experience of the surgeon. Length of hospital stay, if reduced in $\mathrm{RAP}$, is a major factor that could balance costs; however, our analyses indicated that mean hospital stay is similar between OP and RAP, and identical at 1.7 days in the last 100 patients managed using a care pathway targeting discharge on postoperative day 1 . Reduced hospital stay can be reduced by watertight anastomoses and avoidance of the surgical drain, local anesthesia injection in the wound, postoperative analgesia with ketorolac infusion, and a care pathway involving patient awareness of postoperative stay.

Procedural volume is known to affect oncologic and functional outcomes of radical prostatectomy, irrespective of approach. ${ }^{18}$ The main strength of this study is that it provides contemporary data on the outcomes and costs of open and robotic prostatectomy at a single high-volume academic institution. The main limitations are the retrospective nature of the analysis and the lack of validated questionnaires for the postoperative evaluation of functional outcomes.

\section{Conclusion}

Rates of postoperative stress incontinence and erectile dysfunction appear similar in the OP and RAP group. This is particularly true where nerve-sparing approaches are used less frequently in the OP group because of high-risk disease. In addition, while the current study design is not able to provide sufficiently powered comparisons on cancer control outcomes between OP and RAP, positive surgical margins and PSA-free recurrence rates appear to be the same between the 2 approaches, particularly when risk-stratified. Future parallel prospective analysis of sequential robotic cases performed by the same surgeon will address the impact of the learning curve on the surgical, oncologic and functional outcomes of robotic prostatectomy.

Competing interests: Dr. Gagnon, Dr. Lynch and Dr. Hurtado all declare no competing financial or personal interests. Dr. Goldenberg has received consultancy fees from Amgen, Lilly Canada and Abbott Canada. Dr. Gleave is a member of the Advisory Boards for Oncogenex, AstraZeneca, Janssen and Astellas. He is also a member of the Speakers bureau for Janseen and Astellas. He has consultantcy fees from Amgen, Janssen, Astellas and AstraZeneca. He holds a patent for a producted marketed by Oncogenex. He is also a founder and consultant for Oncogenex.

This paper has been peer-reviewed.

\section{References}

1. Statistics Canada, Health Statistics Division, Vital Statistics. http://www.statcan.gc.ca/pub/82624-x/2011001/article/11596-eng.htm. Accessed March 18, 2014.

2. Thompson I, Thrasher JB, Aus G, et al. AUA Prostate Cancer Clinical Guideline Update Panel. Guideline for the management of clinically localized prostate cancer: 2007 update. J Urol 2007;177:2106-31. http://dx.doi.org/10.1016/i.juro.2007.03.003

3. Lowrance WT, Eastham JA, Savage C, et al. Contemporary open and robotic radical prostatectomy practice patterns among urologists in the United States. J Urol 2012;187:2087-92. http://dx.doi. org/10.1016/i.juro.2012.01.061

4. Descazeaud A, Peyromaure M, Zerbib M. Will robotic surgery become the gold standard for radical prostatectomy? Eur Urol 2007;51:9-11. http://dx.doi.org/10.1016/j.eururo.2006.10.007

5. Heidenreich A, Bellmunt J, Bolla $M$, et al. EAU guidelines on prostate cancer. Part 1 : Screening, diagnosis, and treatment of clinically localised disease. Eur Urol 2011;59:61-71. http://dx.doi.org/10.1016/i. eururo.2010.10.039

6. Walsh P, Schaeffer EM, Partin AW, et al. Radical retropubic and perineal prostatectomy. In A. Wein. Campbell-Walsh Urology (10th edition). Philadelphia, PA: Elsevier; 2011.

7. Menon M, Hemal AK, VIP Team. Vattikuti Institute prostatectomy: A technique of robotic radical prostatectomy: Experience in more than 1000 cases. J Endourol 2004;18:611-9; discussion 619. http:// dx.doi.org/10.1089/end.2004.18.611

8. Nelson AL, Cohen JT, Greenberg D, et al. Much cheaper, almost as good: Decrementally cost-effective medical innovation. Ann Intern Med 2009;151:662-7. http://dx.doi.org/10.7326/0003-4819-1519-200911030-00011

9. Hu JC, Gu X, Lipsitz SR, et al. Comparative effectiveness of minimally invasive vs open radical prostatectomy. JAMA 2009;302:1557-64. http://dx.doi.org/10.1001/jama.2009.1451

10. Schroeck FR, Krupski TL, Sun L, et al. Satisfaction and regret after open retropubic or robot-assisted laparoscopic radical prostatectomy. Eur Urol 2008;54:785-93. Epub 2008 Jun 23. http://dx.doi. org/10.1016/i.eururo.2008.06.063

11. Kang DC, Hardee MJ, Fesperman SF, et al. Low quality of evidence for robot-assisted laparoscopic prostatectomy: Results of a systematic review of the published literature. Eur Urol 2010;57:930-7. Epub 2010 Jan 26. http://dx.doi.org/10.1016/i.eururo.2010.01.034

12. Coelho RF, Rocco B, Patel MB, et al. Retropubic, laparoscopic, and robot-assisted radical prostatectomy: A critical review of outcomes reported by high-volume centers. J Endourol 2010;24:2003-15. Epub 2010 Oct 13. http://dx.doi.org/10.1089/end.2010.0295

13. Trinh QD, Sammon J, Sun M, et al. Perioperative outcomes of robot-assisted radical prostatectomy compared with open radical prostatectomy: Results from the nationwide inpatient sample. Eur Urol 2012;61:679-85. Epub 2011 Dec 22. http://dx.doi.org/10.1016/j.eururo.2011.12.027 
14. Tewari A, Sooriakumaran P, Bloch DA, et al. Positive surgical margin and perioperative complication rates of primary surgical treatments for prostate cancer: A systematic review and meta-analysis comparing retropubic, laparoscopic, and robotic prostatectomy. Eur Urol 2012;62:1-15. Epub 2012 Feb 24. http:// dx.doi.org/10.1016/i.eururo.2012.02.029

15. Mohler J, Bahnson RR, Boston B, et al. NCCN clinical practice guidelines in oncology: Prostate cancer. J Natl Compr Canc Netw 2010;8:162-200

16. Heidenreich A, Bellmunt J, Bolla M, et al. EAU guidelines on prostate cancer. Part I: Screening, diagnosis, and treatment of clinically localised disease. Actas Urol Esp 2011;35:501-14. http://dx.doi. org/10.1016/i.acuroe.2011.12.003

17. Ahmed K, Ibrahim A, Wang TT, et al. Assessing the cost effectiveness of robotics in urological surgery - a systematic review. BJU Int 2012;110:1544-56. Epub 2012 Mar 22. http://dx.doi.org/10.1111/ j.1464-410X.2012.11015.x
18. Sammon JD, Karakiewicz PI, Sun M, et al. Robot-assisted versus open radical prostatectomy: The differential effect of regionalization, procedure volume and operative approach. J Urol 2013;189:1289-94. Epub 2012 0ct 22. http://dx.doi.org/10.1016/i.juro.2012.10.028

Correspondence: Dr. Martin E Gleave, The Vancouver Prostate Centre and Department of Urologic Sciences, University of British Columbia, Level 6, 2775 Laurel Street, Vancouver, BC V6H 376; fax: 604-875-5654; m.gleave@ubc.ca 